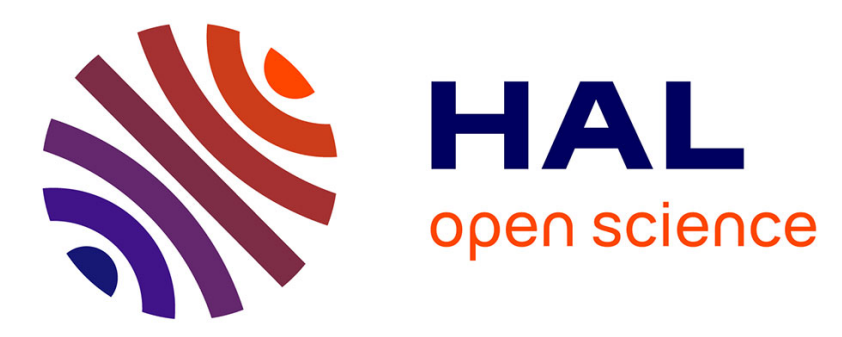

\title{
Lipid nanocapsules: a nanocarrier suitable for scale-up process
}

Olivier Thomas, Frédéric Lagarce

\section{To cite this version:}

Olivier Thomas, Frédéric Lagarce. Lipid nanocapsules: a nanocarrier suitable for scale-up process. Journal of Drug Delivery Science and Technology, 2013, 23 (6), pp.555-559. 10.1016/S17732247(13)50084-0 . hal-03171790

\section{HAL Id: hal-03171790 \\ https://univ-angers.hal.science/hal-03171790}

Submitted on 17 Mar 2021

HAL is a multi-disciplinary open access archive for the deposit and dissemination of scientific research documents, whether they are published or not. The documents may come from teaching and research institutions in France or abroad, or from public or private research centers.
L'archive ouverte pluridisciplinaire HAL, est destinée au dépôt et à la diffusion de documents scientifiques de niveau recherche, publiés ou non, émanant des établissements d'enseignement et de recherche français ou étrangers, des laboratoires publics ou privés. 


\title{
Lipid nanocapsules: a nanocarrier suitable for scale-up process
}

\author{
O. Thomas ${ }^{1}$, F. Lagarce ${ }^{1,2 *}$ \\ ${ }^{1}$ LUNAM Université, Université d'Angers, Inserm U1066-MINT - Micro et Nanomédecines Biomimétiques, \\ IBS-CHU Angers, 4 rue Larrey, F-49933 Angers, France \\ ${ }^{2}$ Pôle SPIP, CHU Angers, 4 rue Larrey, F-49933 Angers, France \\ *Correspondence: frederic.lagarce@univ-angers.fr
}

\begin{abstract}
Nanomedicine is a great hope to enhance the efficacy of drugs and thus the health of many. Unfortunately, while nanotechnology is not new, industrial processing is a major barrier for the market access of nanomedicines. The aim of this work was to study the scale-up possibilities for a very promising formulation; i.e., lipid nanocapsules (LNCs) developed in our laboratory. Pilot-scale batches of ibuprofen LNCs and free-drug LNCs (50 x scale factor) were compared to lab-scale batches. Average diameter, zeta potential and drug loading were determined at the pilot and lab scales. Stability was also studied over time at $4{ }^{\circ} \mathrm{C}$ and room temperature by monitoring size, drug loading and zeta potential over 12 months. It was found that average diameter, zeta potential and drug loading were not significantly different for the pilot and lab scale ( $p<0.05)$. After scale-up, the entrapment efficiency of ibuprofen remained over $97 \%$ and the polydispersity index remained very low $(<0.03)$. The stability study showed a slight increase of LNC diameter along time and a decrease of zeta potential only for free-drug LNCs. In the case of ibuprofen-loaded LNCs, drug loading remained over $96 \%$ throughout the study at $4{ }^{\circ} \mathrm{C}$ and room temperature. These results showed the good ability of LNCs for scale-up without any complex optimization processes. This makes LNCs good candidates for industrial processing and market access.
\end{abstract}

Key words: Lipid nanocapsules - Nanoparticles - Scale-up - Ibuprofen-Production process.

Nanomedicine is a very promising field to enhance the benefits of therapeutic drugs. In fact nanocarriers have shown that they can improve not only the oral bioavailability of many drugs [1] but also their pharmacokinetics and efficacy [2]. While the literature is replete with the pharmacological and toxicological aspects of nanomedicine, only a few papers are dedicated to the production scale-up process of nanoparticles [3, 4]. The first paper [5] dedicated to large-scale production of nanocapsules was published in 2001, less than 15 years ago. Good scale-up is a critical point to assess the quality of industrial batches of nanomedicine. Many challenges remain to assure largescale production of nanomedicine batches compatible with industrial constraints [6]. The main features of nanoparticles - size, drug loading, zeta potential, and drug release ability - have to remain the same from the bench in the lab to the pilot batches. Few commercial forms of nanomedicine have reached the market [2]; this is, for example, the case for Abraxane (paclitaxel/albumin nanoparticles, Abraxis Bioscience) or for Doxil (doxorubicin pegylated liposomes, Janssen), suggesting that the challenges of scale-up can be a limiting factor for market access.

In our laboratory we have developed over the last decade a lipid nanocapsule formulation that has been intended for scale-up from its conception [7,8]. These nanocapsules are obtained by using a very simple process (Figure 1) without the use of organic solvent and using only generally recognized as safe (GRAS) additives that are GMO free [9]. These nanocapsules have shown their ability to encapsulate lipophilic drugs such as paclitaxel [10], sn38 [11], ibuprofen [12], ferrociphenol [13], etoposide [14], and also hydrophilic drugs such as doxorubicin hydrochloride [15] or erlotinib [16]; and biomacromolecules such as DNA [17] or SiRNA [18], thus making these nanocapsules a good platform for nanomedicine [19]. In order to prepare preclinical batches of paclitaxel nanocapsules to determine their efficacy and toxicity, first a 10 -fold scale-up procedure was implemented [20]. The goal of the present study was to set up and evaluates a much larger (50-fold) scale-up process. The obtained nanocapsules were characterized in terms of average diameter, zeta potential and drug loading in order to check that their properties were maintained after the scale-up procedure.

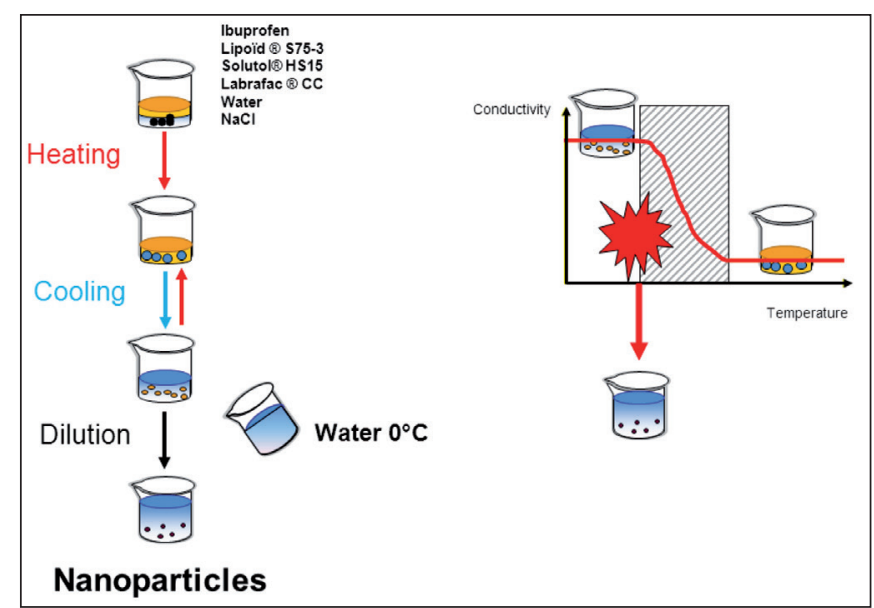

Figure 1 - Formulation process of lipidic nanocapsules (from [12]).

\section{MATERIALS AND METHODS 1. Materials}

Ibuprofen was purchased from Sigma (Steinheim, Germany), Labrafac CC; i.e., medium chain triglycerides (C8-C10 fatty acids), was kindly provided by Gattefossé (Saint-Priest, France). Lipoïd S75-3 (soybean lecithin) and Solutol HS15 (polyethylene glycol-660 hydroxystearate) were kind gifts from Lipoïd GmbH (Ludwigshafen, Germany) and BASF AG (Ludwigshafen, Germany), respectively. All other chemical reagents were obtained from Sigma (Steinheim, Germany) and Prolabo (Fontenay-sous-Bois, France) and were of analytical grade. De-ionized water was obtained from a Milli RO System (Millipore, Paris, France).

\section{LNC preparation}

The preparation of LNCs was based on a phase inversion method that allows for the preparation of very small nanocapsules by thermal manipulation of an oil/water system [7]. Briefly, 1,013 mg of Labrafac CC were mixed with $845 \mathrm{mg}$ of Solutol HS 15, $75 \mathrm{mg}$ of Lipoïd S75-3, 
$89 \mathrm{mg}$ of sodium chloride, and 3,000 mg distilled water and heated under magnetic stirring to $90{ }^{\circ} \mathrm{C}$ (until a distinct drop of conductivity occurred) ensuring that the phase inversion temperature was exceeded. The cooling step was then performed until a temperature close to $60{ }^{\circ} \mathrm{C}$ was reached, again, completely passing the phase inversion zone. This cycle was repeated twice before adding $12.5 \mathrm{~mL}$ of distilled water at $2{ }^{\circ} \mathrm{C}$ when the mixture was at $75{ }^{\circ} \mathrm{C}$. The LNCs production at laboratory scale was performed on a heated magnetic stirring plate. Heating-cooling cycles (typically carried out at a rate of $4{ }^{\circ} \mathrm{C} / \mathrm{min}$ ) and stirring were not reproducible; so, heating step was performed at a rate higher than $4{ }^{\circ} \mathrm{C} / \mathrm{min}$ and cooling step was performed at a rate lower than $4{ }^{\circ} \mathrm{C} / \mathrm{min}$.

For ibuprofen-loaded nanocapsules, $100 \mathrm{mg}$ of ibuprofen were dissolved, under agitation, in $913 \mathrm{mg}$ of the internal oily triglyceride phase prior to all preparation steps by heating at $37^{\circ} \mathrm{C}$ for $60 \mathrm{~min}$ [12]. The above mentioned procedure was then applied to the mixture. All experiments were performed in triplicate.

\section{Pilot-scale production}

Scale-up production was carried out by increasing 50 fold the material used for laboratory batches.

The equipment used for pilot-scale production is based on the automatic reactor ARLA1, marketed by Algochem Company (Paris, France). It was composed of two double-jacketed reactors (Figure 2). The first reactor, in which the cooling-heating cycles are performed, had a total capacity of $250 \mathrm{~mL}$ and was equipped with three-bladed propeller. The second one had a total capacity of $1,000 \mathrm{~mL}$ and was also equipped with three-bladed propeller. Unlike trials at laboratory scale, each reactor was controlled automatically in terms of temperature, agitation and time. The main characteristics of the pilot-scale production process are presented in Table I and compared to the lab-scale.

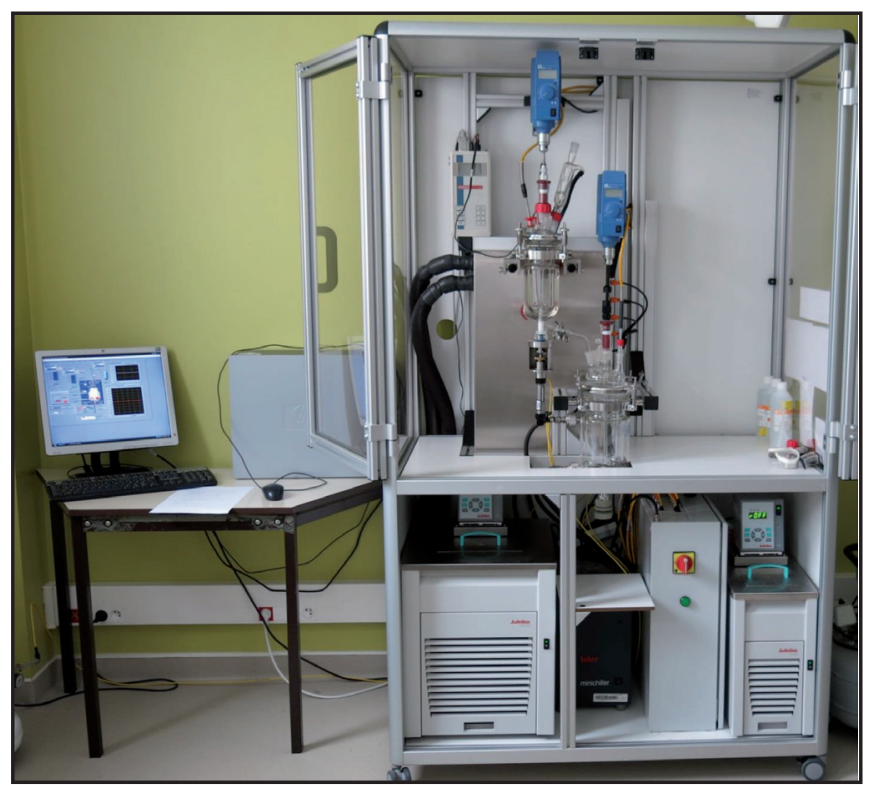

Figure 2 - Equipment used to obtain pilot-scale batches of lipid nanocapsules (ARLA1, Algochem).

\section{Characterization of lipid nanocapsules}

\subsection{Particle size and surface charge}

LNCs were characterized for average diameter based on intensity distributions, polydispersity index and charge distribution by dynamic light scattering using a Zetasizer Nano Series DTS 1060 (Malvern Instruments S.A., Worcestershire, United Kingdom). LNCs were diluted 1:60 (v/v) in deionized water in order to ensure a convenient scatter intensity on the detector. Measurements were performed in triplicate for each point.

\subsection{Drug loading}

Determination of drug loading was achieved by spectrophotometry. LNCs were separated from supernatant using Amicon Ultra $4 \mathrm{~mL}$ $10 \mathrm{KDa}$ microcentrifugal filters (Merck Millipore Ltd., Tullagreen, Carrigtwohill, County Cork, Ireland). Ibuprofen concentration was measured in supernatant by spectrophotometry at $269 \mathrm{~nm}$ using an Uvikon 922 Spectrophotometer (Bio-Tek Kontron Instruments, Saint-Quentin-en-Yvelines, France). Quantification was achieved by comparing the absorbance at $269 \mathrm{~nm}$ of ibuprofen sample to a calibration curve established in linear range $5-500 \mu \mathrm{g} / \mathrm{mL}$. The experimental drug payload was determined as the difference between the theoretical drug payload and the ibuprofen concentration dosed in the supernatant. The encapsulation efficiency (\%) was determined by dividing the experimental drug payload by the theoretical drug payload. Samples were performed in triplicate.

\section{Stability study}

The stability of nanocapsule suspensions during storage at $4{ }^{\circ} \mathrm{C}$ and room temperature was assessed by measuring size distribution, polydispersity and the zeta potential, for one year as stated before in the text.The stability of encapsulation (i.e., drug loading consistency) was also evaluated for one year by spectrophotometry as described above.

\section{Statistics}

The data are presented as mean \pm standard deviation of three different experiments. The Mann Whitney U test was used to compare the means, a $p$ value $<0.05$ was considered a significant difference between means.

\section{RESULTS}

\section{Preparation of LNCs at the lab-scale and pilot-scale}

Free-drug LNCs and ibuprofen-loaded LNCs were successfully prepared at the lab and pilot scales. The characteristics of the obtained nanoparticles are displayed in Table II. Ibuprofen-loaded LNCs were found to be smaller than free-drug LNCs ( $\mathrm{p}<0.05)$, but no significant differences were found between lab-scale LNCs and pilot-scale LNCs for all characteristics in both groups (free-drug and ibuprofen-loaded LNCs). Thus, pilot-scale process allowed for similar LNCs to lab-scale process to be obtained. Entrapment efficiency was found high both for lab-scale and pilot-scale LNCs ( $p>0.05)$.

\section{Stability study of LNCs prepared at the lab-scale and pilot-scale}

The on-shelf stability of LNCs was assessed for one year for both techniques of preparation (lab-scale and pilot-scale). The aver-

Table I - Equipment used to prepare LNCs at laboratory and pilot scales.

\begin{tabular}{|c|c|c|c|c|}
\hline \multirow[t]{2}{*}{ Steps } & \multicolumn{2}{|c|}{ Laboratory } & \multicolumn{2}{|l|}{ Pilot } \\
\hline & Recipient & Agitation & Recipient & Agitation \\
\hline $\begin{array}{l}\text { Pre-emulsification } \\
\text { Emulsification } \\
\text { Dilution }\end{array}$ & $\begin{array}{l}\text { Scintillation vial }(20 \mathrm{~mL}) \\
\text { Scintillation vial }(20 \mathrm{~mL}) \\
\text { Scintillation vial }(20 \mathrm{~mL})\end{array}$ & $\begin{array}{l}\text { magnetic } \\
\text { magnetic } \\
\text { magnetic }\end{array}$ & $\begin{array}{c}\text { Beaker }(250 \mathrm{~mL}) \\
\text { Double-jacketed reactor }(250 \mathrm{~mL}) \\
\text { Double-jacketed reactor }(1000 \mathrm{~mL})\end{array}$ & $\begin{array}{l}\text { magnetic } \\
\text { Three-bladed propeller } \\
\text { Three-bladed propeller }\end{array}$ \\
\hline
\end{tabular}


Table II - Characteristics of LNCs obtained at laboratory and pilot scales with or without ibuprofen.

\begin{tabular}{|c|c|c|c|}
\hline \multirow{2}{*}{$\begin{array}{c}\text { Nanoparticles } \\
\text { characteristics }\end{array}$} & \multicolumn{2}{|c|}{ Free-drug LNCs } & \multicolumn{2}{c|}{ Ibuprofen-loaded LNCs } \\
\cline { 2 - 4 } & Lab-scale & Pilot-scale & Lab-scale \\
\hline Mean diameter (nm) & $55.80 \pm 0.97$ & $58.07 \pm 2.67$ & $49.00 \pm 1.63$ \\
Polydispersity index & $0.034 \pm 0.006$ & $0.078 \pm 0.007$ & $0.043 \pm 0.022$ \\
Zeta potential (mV) & $-5.15 \pm 0.30$ & $-5.14 \pm 1.59$ & $-3.70 \pm 0.19$ \\
Entrapment efficiency (\%) & - & - & $97.52 \pm 0.55$ \\
\hline
\end{tabular}

age diameter and the zeta potential of the LNCs along time at room temperature and $4{ }^{\circ} \mathrm{C}$ are presented in Figures 3 and 4 , respectively. The polydispersity index remained below 0.2 for all batches tested during for one year. Some data are missing for the long-term study; this was due to the bacterial or fungal contamination of the suspensions that were not sterilized. The monitoring of drug loading along time at room temperature and $4{ }^{\circ} \mathrm{C}$ is presented in Figure 5. Drug loading was maintained over $96 \%$ for one year for lab-scale and pilot-scale formulations at $4{ }^{\circ} \mathrm{C}$ and room temperature.

\section{DISCUSSION}

The initial aim of this study was to produce ibuprofen nanocapsules in large batches, following a previous preliminary production process that was published a few years ago [12]. The characteristics of ibuprofen LNCs (average diameter, zeta potential, drug loading and encapsulation efficiency) were kept the same between this previous work and the present study. The average diameter decrease observed between free drug LNCs and ibuprofen LNCs is explainable in the case of ibuprofen LNCs as the amount of labrafac is reduced relatively to the other compounds. In fact, in ibuprofen-loaded LNCs, the mass of labrafac was decreased to take into account the mass of added ibuprofen. The formulation parameters of this process are now well understood and mastered and this is a condition to consider in the scale-up of the process.

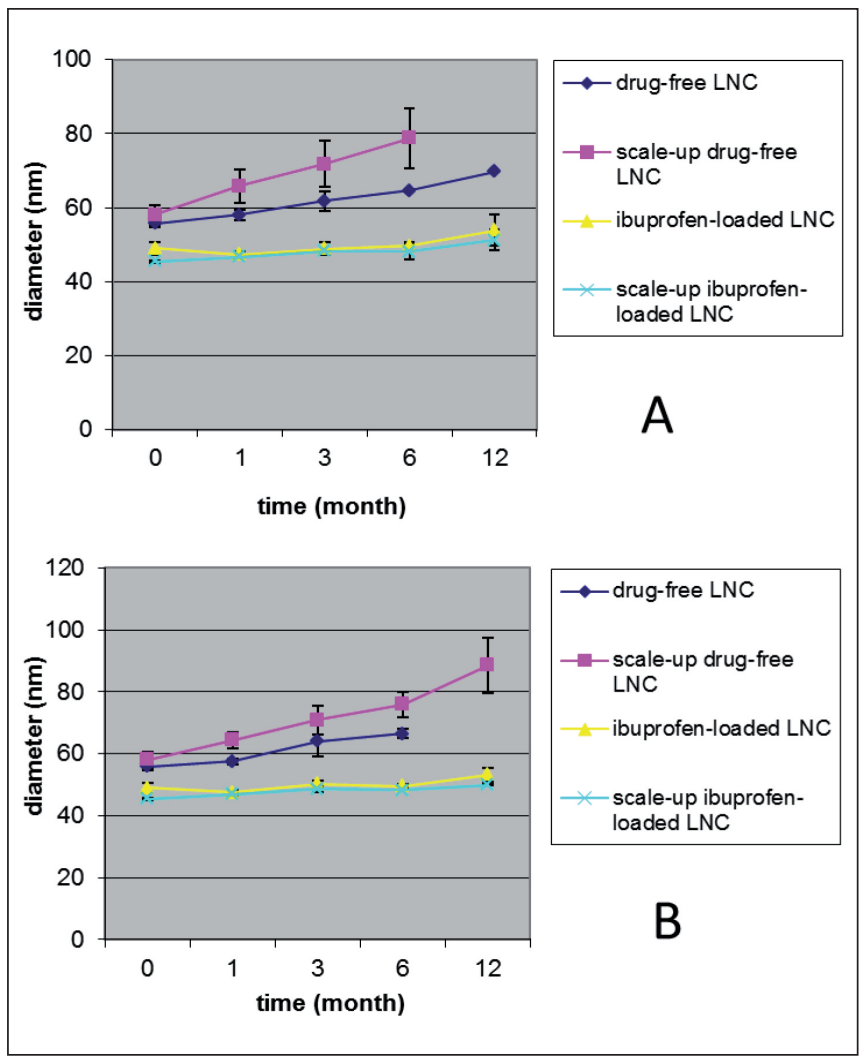

Figure 3 - Evolution of nanocapsule size over time at room temperature (A) and $4^{\circ} \mathrm{C}(\mathrm{B})$.
In fact, scale-up is an important step in order to allow the market access of new drug delivery systems. For nanomedicine, this step can be very complex and often impairs the future of the most innovative nanocarriers. Scale-up ability is linked to the production process. This was shown by a study comparing three different methods for producing ibuprofen nanoparticles: salting-out, emulsification-diffusion and nanoprecipitation [3]. In this study, the nanoprecipitation method was less suitable for scale-up in comparison to salting-out and emulsification-diffusion; for example, the size of the nanoparticles obtained after pilot-scale process was smaller $(105 \pm 8 \mathrm{~nm})$ than the batches obtained at the lab-scale $(141 \pm 5 \mathrm{~nm})$. The entrapment efficiency was also smaller for pilot-scale batches for the three methods but the relative difference was higher in the case of nanoprecipitation. Our process was initially designed to be suitable for large-scale production as it needed only low energy and was not dependent on the stirring characteristics as is, for example, the case for emulsification-diffusion process [3, 21]. In fact, in our process the stirring is only used to homogenate the medium where the phase inversion occurs while the temperature is changed. Stirring is not used to bring energy to the system in order to obtain an emulsion or a nanoemulsion. In these cases, the stirring mode has an important impact on the size of the particles [22]. Thus, to obtain good results after scale-up, the energy patterns between labscale volume and pilot volume should be the same, which is difficult to obtain.

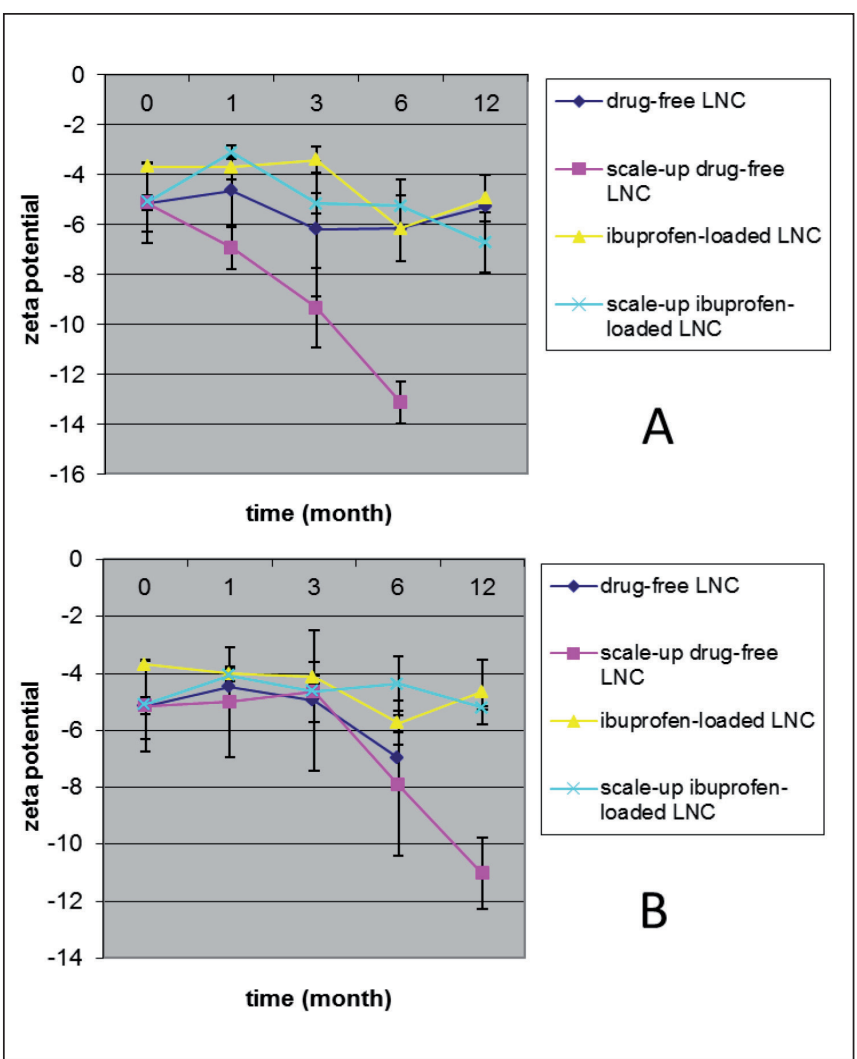

Figure 4 - Evolution of LNC zeta potential over time at room temperature $(\mathrm{A})$ and $4{ }^{\circ} \mathrm{C}(\mathrm{B})$. 


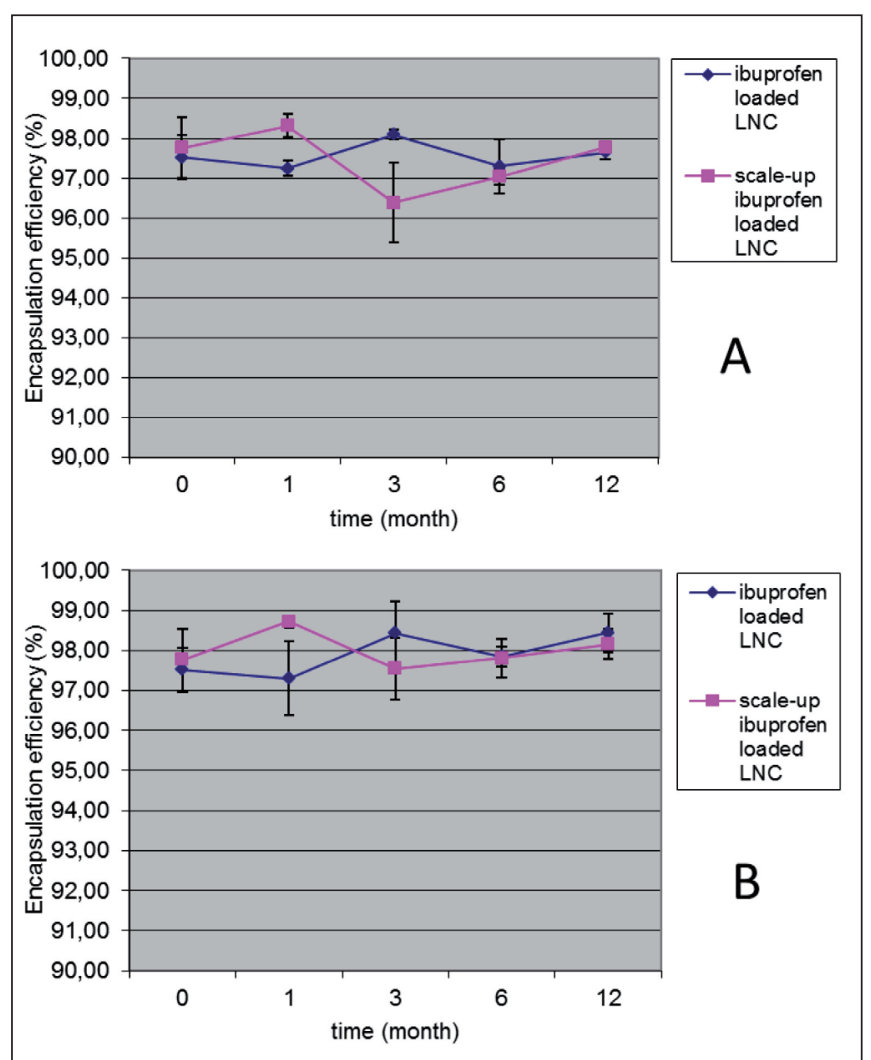

Figure 5 - Evolution of LNC drug loading over time at room temperature (A) and $4{ }^{\circ} \mathrm{C}(\mathrm{B})$

Interestingly, our process allowed us to obtain good quality pilotscale batches without optimizing the process along the scale-up. In fact, to go from lab-scale to pilot-scale, a $50 \times$ factor was applied to the amount of all chemicals used in the formulation. Only the material (i.e., heating/cooling process, volumes, etc.) had to be designed for the pilot-scale. At the laboratory scale, the two steps of LNC formulation, i.e., heating-cooling cycles and dilution, were performed in the same vessel, a $20 \mathrm{~mL}$ vial. Magnetic agitation enabled a small volume at the beginning to be mixed and then also the LNC suspension after the dilution step. For pilot-scale batches, two distinct reactors were used in order to overcome complicated design of the equipment. Indeed, it was difficult to design a reactor in which it was possible to stir a small volume at the beginning and a much larger one at the end while maintaining correct homogenization of the medium. We chose to perform the first step in a $250 \mathrm{~mL}$ reactor, controlled automatically in terms of temperature, agitation and time, and to add by gravity the medium in a second reactor containing the dilution water (Figure 2). This ability to go easily from lab-scale to pilot-scale by geometric scale-up is not often described. For example, curcumin C3 complex-loaded nanoparticles, prepared by solvent evaporation/diffusion method, had to be optimized in four stages in order to obtain a $50 \times$ scale-up [21]. In this case, the relative amounts of the solvents changed along the scale-up stages, the sonication time and other formulation factors had to also be optimized for each stage. In other studies, a membrane contactor had to be used in order to obtain pilot-scale batches close to the lab-scale batches for liposomes and niosomes containing caffeine and spironolactone [23] and for vitamin E nanocapsules [24]. For solid lipid nanoparticles (SLNs), some very large scale-up batches have been obtained by high pressure homogenization (HPH) and have been found stable along time [25]. HPH is well adapted to the production of SLNs but not to the production of LNCs. Mixing has often to be adapted to obtain large-scale batches. Static mixers have been used in order to obtain a continuous flow production of nanoparticles with success [26, 27] and can be a solution to obtain very large scale batches. Our process is not adapted to static mixing, thus continuous flow production is not possible today, but our process is fast and simple. A $50 \times$ scale-up batch takes only $2 \mathrm{~h}$ to obtain, and time is not proportional to quantity; for this reason, much larger scale batches and multiple production can be considered for industrial production of lipid nanocapsules.

The scale-up process can change the stability of the nanoparticles; it is thus important to check the stability of the pilot-scale batches along time. Our results showed that the stability of lab-scale and pilot-scale batches was comparable. The ibuprofen LNCs displayed a better stability in comparison to free-drug LNCs. The size increase observed along the one year stability study being greater on free-drug LNCs is due to Ostwald ripening. This phenomenon was found to have only a minor effect on ibuprofen-loaded LNCs as the active ingredient stabilized the oily core of nanocapsules. Similarly, Ostwald ripening could be responsible for the decrease in zeta potential observed on free-drug LNCs because the migration of oil molecules is thought to induce a change of conformation of the polyethylene glycol shell constituting nanocapsules and, thus, the value of the surface potential.

The ability of the LNC manufacturing process for scale-up has also been verified very recently for etoposide nanocapsules [14].

This study showed that lipid nanocapsule technology is well adapted to scale-up without a complex optimization study. Large-scale batches were obtained and the characteristics of the LNCs were maintained after scale-up and also along time for 12 months. The nanocapsules have previously shown their ability for freeze drying [28] and are well tolerated in animal studies [20]. All these features make LNCs good candidates for market access.

\section{REFERENCES}

1. Roger E., Lagarce F., Garcion E., BenoitJ.P. - Biopharmaceutical parameters to consider in order to alter the fate of nanocarriers after oral delivery. - Nanomedicine (Lond.), 5, 287-306, 2010.

2. Kim B.Y., Rutka J.T., Chan W.C. - Nanomedicine. - N. Engl. J. Med., 363, 2434-2443, 2010.

3. Galindo-Rodriguez S.A., Puel F., Briancon S., Allemann E., Doelker E., Fessi H. - Comparative scale-up of three methods for producing ibuprofen-loaded nanoparticles. - Eur. J. Pharm. Sci., 25, 357-367, 2005.

4. Mitri K., Vauthier C., Huang N., Menas A., Ringard-Lefebvre C., Anselmi C., Stambouli M., Rosilio V., Vachon J.-J., Bouchemal K. - Scale-up of nanoemulsion produced by emulsification and solvent diffusion. - J. Pharm. Sci., 101, 4240-4247, 2012.

5. Colombo A.P., Briancon S., Lieto J., Fessi H. - Project, design, and use of a pilot plant for nanocapsule production. - Drug Dev. Ind. Pharm., 27, 1063-1072, 2001.

6. Muthu M.S., Wilson B. - Challenges posed by the scale-up of nanomedicines. - Nanomedicine, 7, 307-309, 2012.

7. Heurtault B., Saulnier P., Pech B., Proust J.E., Benoit J.P. - A novel phase inversion-based process for the preparation of lipid nanocarriers. - Pharm. Res., 19, 875-880, 2002.

8. Benoit J.P., Heurtault B., Pech B., Proust J.E., Richard J., Saulnier P. - Nanocapsules lipidiques, procédé de préparation et utilisation comme médicament. - Patent WO 0164328 (A1), 2001.

9. Hureaux J., Lagarce F., Gagnadoux F., Clavreul A., Benoit J.P., Urban T. - The adaptation of lipid nanocapsule formulations for blood administration in animals. - Int. J. Pharm., 379, 266-269, 2009.

10. Roger E., Lagarce F., Garcion E., Benoit J.P. - Lipid nanocarriers improve paclitaxel transport throughout human intestinal epithelial cells by using vesicle-mediated transcytosis. - J. Control. Release, 140, 174-181, 2009.

11. Roger E., Lagarce F., Benoit J.P. - Development and characterization of a novel lipid nanocapsule formulation of Sn38 for 
oral administration. - Eur. J. Pharm. Biopharm., 79, 181-188, 2011.

12. Lamprecht A., Saumet J.L., Roux J., Benoit J.P. - Lipid nanocarriers as drug delivery system for ibuprofen in pain treatment. - Int. J. Pharm., 278, 407-414, 2004.

13. Laine A.L., Huynh N.T., Clavreul A., Balzeau J., Bejaud J., Vessieres A., Benoit J.P., Eyer J., Passirani C. - Brain tumour targeting strategies via coated ferrociphenol lipid nanocapsules. - Eur. J. Pharm. Biopharm., 81, 690-693, 2012.

14. Saliou B., Thomas O., Lautram N., ClavreulA., Hureaux J., Urban T., Benoit J.P., Lagarce F. - Development and in vitro evaluation of a novel lipid nanocapsule formulation of etoposide. - Eur. J. Pharm. Sci., 50, 172-180, 2013.

15. Vrignaud S., Anton N., Passirani C., Benoit J.P., Saulnier P. Aqueous core nanocapsules: a new solution for encapsulating doxorubicin hydrochloride. - Drug Dev. Ind. Pharm., 39 (11) 1706-1711, 2013

16. Vrignaud S., Hureaux J., Wack S., Benoit J.P., Saulnier P. Design, optimization and in vitro evaluation of reverse micelleloaded lipid nanocarriers containing erlotinib hydrochloride. - Int. J. Pharm., 436, 194-200, 2012.

17. Morille M., Montier T., Legras P., Carmoy N., Brodin P., Pitard B., Benoit J.P., Passirani C. - Long-circulating DNA lipid nanocapsules as new vector for passive tumor targeting. - Biomaterials, 31, 321-329, 2010.

18. David S., Passirani C., Carmoy N., Morille M., Mevel M., Chatin B., Benoit J.P., Montier T., Pitard B. - DNA nanocarriers for systemic administration: characterization and in vivo bioimaging in healthy mice. - Mol. Ther. Nucleic Acids, 2, e64, 2013.

19. Huynh N.T., Passirani C., Saulnier P., Benoit J.P. - Lipid nanocapsules: a new platform for nanomedicine. - Int. J. Pharm., 379, 201-209, 2009.

20. Hureaux J., Lagarce F., Gagnadoux F., Rousselet M.C., Moal V., Urban T., Benoit J.P. - Toxicological study and efficacy of blank and paclitaxel-loaded lipid nanocapsules after i.v. administration in mice. - Pharm. Res., 27, 421-430, 2010.

21. Ranjan A.P., Mukerjee A., Helson L., Vishwanatha J.K. - Scale up, optimization and stability analysis of Curcumin C3 complexloaded nanoparticles for cancer therapy. - J. Nanobiotechnology, 10, 38, 2012.
22. YeZ., Squillante E. - The development and scale-up of biodegradable polymeric nanoparticles loaded with ibuprofen. - Colloids and Surfaces a-Physicochemical and Engineering Aspects, 422, 75-80, 2013.

23. Pham T.T., Jaafar-Maalej C., Charcosset C., Fessi H. - Liposome and niosome preparation using a membrane contactor for scale-up. - Colloids Surf B Biointerfaces, 94, 15-21, 2012.

24. Khayata N., Abdelwahed W., Chehna M.F., Charcosset C., Fessi H. - Preparation of vitamin E loaded nanocapsules by the nanoprecipitation method: from laboratory scale to large scale using a membrane contactor. - Int. J. Pharm., 423, 419-427, 2012.

25. Shegokar R., Singh K.K., Muller R.H. - Production \& stability of stavudine solid lipid nanoparticles--from lab to industrial scale. - Int. J. Pharm., 416, 461-470, 2011.

26. Dong Y., Ng W.K., Hu J., Shen S., Tan R.B. - A continuous and highly effective static mixing process for antisolvent precipitation of nanoparticles of poorly water-soluble drugs. - Int. J. Pharm., 386, 256-261, 2010.

27. Dong Y., Ng W.K., Shen S., Kim S., Tan R.B. - Solid lipid nanoparticles: Continuous and potential large-scale nanoprecipitation production in static mixers. - Colloids and Surfaces B-Biointerfaces, 94, 68-72, 2012.

28. Dulieu C., Bazile D. - Influence of lipid nanocapsules composition on their aptness to freeze-drying. - Pharm. Res., 22, 285-292, 2005.

\section{ACKNOWLEDGEMENTS}

This work was supported by a grant entitled "ANR CALIF" provided by the National French Research Agency.

\section{MANUSCRIPT}

Received 8 April 2013, accepted for publication 26 June 2013. 
